\title{
Association of epileptiform brain activity and specific language impairment (SLI) in preschool children
}

\author{
Ahmed Esmael ${ }^{1 *}$ D, Sara Elsherbeny ${ }^{2}$ and Mohammed Abbas $^{1}$
}

\begin{abstract}
Background: Epileptiform activities can cause transient or permanent deficits that affect the children during development and may be accompanied by neurodevelopmental disorders like specific language impairment.

Objectives: The objective of this study was to find if there is a possible association and the impact of epilepsy and epileptiform activity in children with specific language impairment.

Patients and methods: The study was conducted on 80 children suffering from specific language impairment and 80 age and sex match healthy control children. Computed tomography brain was performed and electroencephalography was recorded for children. Intelligence quotient level, cognitive age, social, and phoniatric assessment were done for all patients.

Results: Eighty children with specific language impairment (51 males and 29 females) with a mean age of $4.11 \pm 1.93$. Patients with specific language impairment showed significantly higher rates of abnormal electroencephalography $(P=0.006)$ and epilepsy $(P<0.001)$ compared to the control group. Spearman correlation demonstrated a highly negative significant relationship linking the language, intelligence quotient with abnormal electroencephalography and epilepsy ( $r=-0.91, P<0.01$ and $r=-0.91, P<0.01$ respectively). Also, there was a moderately inverse significant relationship linking the cognitive age, social with abnormal electroencephalography, and epilepsy $(r=-0.70, P<0.05$ and $r=-0.65, P<0.05$ respectively).
\end{abstract}

Conclusion: Epileptiform activities even without epilepsy in preschool children may alter normal language function. Specific language impairment was associated with lower intelligence quotient levels, social, and cognitive age.

Trial registration: ClinicalTrials.gov ID: NCT04141332

Keywords: Specific language impairment, Epilepsy, EEG, Language assessment

\section{Introduction}

Specific language impairment (SLI) is characterized by delayed or impaired language development in children with no primary physical disabilities, neurological disorder, or mental illness [1]. Neurobiology and genetics studies offer a delimited but critical window into understanding the complex causal mechanisms associated with SLI $[2,3]$. Multifactorial elements were incriminated in the development of SLI as a social, environmental, and

\footnotetext{
* Correspondence: deltaneuro@yahoo.com

${ }^{1}$ Departments of Neurology, Mansoura University, Mansoura, Egypt

Full list of author information is available at the end of the article
}

genetic influence [4]. Ghandour and colleagues 2018 mention that SLI is a neurodevelopmental disorder that affects around $3-7 \%$ of children [5]. Severe SLI will prevent the child from participating in several social and academic interactions $[4,6]$.

Cognitive functions were found to be affected greatly among children with epilepsy [7]. About $50 \%$ of epileptic patients have epileptiform discharge [8]. Epileptiform activities (EPFA) can cause transient or permanent deficits with higher effects in children during development more than in a mature brain [9].

\section{Springer Open}

() The Author(s). 2021 Open Access This article is licensed under a Creative Commons Attribution 4.0 International License, which permits use, sharing, adaptation, distribution and reproduction in any medium or format, as long as you give appropriate credit to the original author(s) and the source, provide a link to the Creative Commons licence, and indicate if changes were made. The images or other third party material in this article are included in the article's Creative Commons licence, unless indicated otherwise in a credit line to the material. If material is not included in the article's Creative Commons licence and your intended use is not permitted by statutory regulation or exceeds the permitted use, you will need to obtain permission directly from the copyright holder. To view a copy of this licence, visit http://creativecommons.org/licenses/by/4.0/. 
In these patients, interictal epileptiform discharges (IED) (spikes) are found on electroencephalography (EEG) and believed to be accompanied by temporary cognitive impairments. Explaining the connection between these electrophysiological characters and their functional impacts is an important step in advance in improving treatment and quality of life for those patients [10]. Hyperexcitability prompts damaged neuronal functions and impairment of cognition [11, 12]. Also, Edward Faught and colleagues 2018 reported that IED causes a chain of events that resulted in brain dysfunction [13].

Laura Escamilla and José González 2019 mention that the presence of epileptiform discharge was accompanied by neurodevelopmental disorders like SLI and autism; however, it is obscure whether their association is causal or an epiphenomenon. The answer to this inquiry is vital since it would help to decide the treatment [14].

This study concentrates on the impact of epileptiform activity for childhood epilepsy on speech and language disturbances in addition to the associated social, cognitive, and intellectual dysfunctions. These data have been presented previously as an abstract of the 6th Congress of the European Academy of Neurology, Virtual 2020 [15].

\section{Methods}

The study was conducted on 80 children with speech disorders in preschool children who attended the outpatient clinic of neurology and phoniatric departments, during the period February 2018 to March 2019. Consent from the parents of the patient was taken to participate in this study, which was approved by the local ethics committee Institutional Research Board (IRB) of our departments of neurology. Code RP. 19.10.45 date 30 October 2019. These children were suffering from expressive language abnormalities and combined expressive-receptive language disorders. Control group were 80 healthy children with age and sex match. The age was about 3-6 years. Previous history of perinatal hypoxic-ischemic damage, meningitis or encephalitis, motor weakness, hearing disorders, intelligence quotient (IQ) below seventy, cerebral palsy (CP), social deprivation, autism, and psychiatric disorders were considered as an exclusion criterion.

Participants underwent an evaluation with detailed history, developmental status analysis, and a comprehensive examination. Computed tomography (CT) brain was done for all patients and MRI brain was carried out for all patients with epileptiform activity or with suspected lesion in CT brain.

Electroencephalogram was done for all patients to document the presence or absence of any epileptiform activity. An electroencephalogram (EEG) was carried out using the 10-20 international system for about 20 min under standard conditions and by using provocative techniques like hyperventilation and photic stimulation. Recordings were performed using EB Neuro Basis BE Hardware (Firenze, Italy) and Galileo Software (Firenze, Italy) for EEG data acquisition and review.

Because children have a tendency to move during EEG acquisition, electrode application should be carried out with high care. All 21 electrodes of the International 10-20 system should be used. Especially active children may need more recurrent check of electrode recording quality. The voltage of EEG activity in children is higher than that of adults, and a decrease of sensitivity to $10-15 \mathrm{mV} / \mathrm{mm}$ could be used. Hyperventilation was done at the start of EEG recording and photic stimulation at the end. In older children, EEG acquisition may involve periods with open and closed eyes. Sleep recordings are preferred, with continuous EEG recording rather than pausing in between states (waking vs. drowsy vs. sleep) and should be indicated clearly at the start of the EEG acquisition with each montage [16].

EEGs finding were defined according to the following $[17,18]$ :

"Normal: is within the range of frequency and amplitude distribution".

"Epileptiform: describes transient background activity with characteristic spikes, sharp waves, spike slow-wave or sharp slow-wave complexes of focal or generalized distribution" and the background abnormality not matched with the state and age of the child.

"Abnormal without epilepsy: deviations from normal in terms of background frequency patterns, usually in the form of excessive slow activity".

"Epilepsy is defined as a group of neurological disorders characterized by repetitive attacks of epileptic seizures [19]. An epileptic seizure is a transient incidence of signs and/or symptoms due to abnormal synchronous neuronal activity in the brain [20].

The International League Against Epilepsy (ILAE) official reported in 2017 that epilepsy is considered if two or more seizures occurring $>24 \mathrm{~h}$ apart, one unprovoked seizure and a probability of recurrent seizure risk more than $60 \%$ [19]. If there is any epileptiform discharge on EEG, or a potential epileptogenic structure on brain imaging, the probabilities of repetitive epileptic attack more than $60 \%$ [21]".

Phoniatric assessment was carried out for all participants. Evaluation of cognitive age (mental age): using the Stanford-Binet Intelligence Scale Fifth Edition (SB5) classification of the IQ [22]: 


\begin{tabular}{ll}
\hline IQ range & Classification \\
$145-160$ & (Highly advanced) \\
$130-144$ & (Very advanced) \\
$120-129$ & (Superior) \\
$110-119$ & (High average) \\
$90-109$ & (Average) \\
$80-89$ & (Low average) \\
$70-79$ & (Borderline impaired) \\
$55-69$ & (Mildly impaired) \\
$40-54$ & (Moderately impaired) \\
\hline
\end{tabular}

Evaluation of social age: using the Vineland Social Maturity Scale [23]. The Vineland Social Maturity Scale (VSMS) estimates the social abilities. It gives a measure of social age (SA) and social quotient (SQ). VSMS scans social abilities among kids in the areas of self-help general, self-help eating, self-help dressing, self-direction, occupation, communication, locomotion, and socialization.

The VSMS is formed of 89 test sub-items grouped according to year levels and consists of group of questions for children of each completed year ranged from 0 up to 15 years. Compute social quotient (SQ) by dividing social age by chronological age and multiplying by 100 .

Language evaluation by Comprehensive Arabic Language Test (CALT) [24] which is a test battery composed of five subtests.

Test of phonology that consists of 71 words. Each Arabic phoneme is evaluated in a variable position and the articulation of the corresponding picture is assessed. Test of semantics includes 214 items. Recognize and name: different semantic groups as vegetables, clothes, and fruits. Also, variable concepts as direction, quantity, time, and matching. Test of the morphology consist of 56 questions. Variable morphological structures as personal pronouns, verb tense, negation, and derivation. Test of the syntax include the receptive syntactic ability is (repeating 10 sentences, following 8 directives, and answering 7 questions. The expressive syntactic ability is describing 10 actions, sequencing 4 events, and finally test of pragmatics consists of 42 questions indicating different speech act as requesting, regulating, informing, and expressing. The core of each subtest is the sum of the correct answers.

A score of 2 or more standard deviation (SD) below the test mean of CALT and the VSMS is considered impaired.

\section{Statistical analysis}

Information and findings of the present study were analyzed with computed SPSS version 21 (SPSS, version
21; SPSS Inc., Chicago, IL, USA). Continuous data were expressed in the form of mean \pm SD while categorical data were expressed in the form of numbers and \%. Continuous data were compared by utilizing Student's $t$ test, while categorical comparison was done utilizing chi-square test. For abnormally distributed data, a comparison between the two groups was made using the Mann-Whitney test. The frequency of EEG abnormality in the two groups was related to statistical significance. $P$ value of 0.05 or less is considered of statistical significance. The correlation of abnormal EEG activity and SLI, IQ, cognitive age, and social age was performed by Spearman correlation analysis.

\section{Results}

Eighty children with SLI in preschool children included 51 males and 29 females with a mean age of $4.11 \pm 1.93$ and normal CT and MRI brain. Eighty children of matched age and gender were considered as control. Patients with SLI showed higher rates of abnormal EEGs (26.2\%) in comparison to the control group (6.2\%), $P=$ 0.006 (Table 1). The coexistence of seizures among SLI patients was significant compared to control group $P<$ 0.001 (Fig. 1).

In our study, 17 patients with SLI were epileptic, 5 patients with generalized (tonic and clonic) epilepsy, 2 patients with myoclonic epilepsy, 2 patients with absence epilepsy, 5 patients with temporal epilepsy, 2 patients with benign childhood epilepsy, and 1 patient with unclassified epilepsy (Table 2).

IQ levels were strongly correlated to epileptiform discharge. Seventeen of the 21 cases with abnormal EEGs showed lower IQ levels range (70-79 and 80-89) and $P<$ 0.005 . While 44 of the 59 cases with normal EEGs showed a significantly higher IQ level range (90-99 and 100-109) and $P$ value is 0.002 and 0.09 respectively (Fig. 2).

Table 1 Demographic characteristics and EEG activity among patients with SLI and controls

\begin{tabular}{llll}
\hline Variable & Patients & Controls & $P$ value \\
\hline $\begin{array}{l}\text { Number } \\
\text { Sex }\end{array}$ & 80 & 80 & - \\
$\quad$ Male & 51 & 50 & $X 20.027$ \\
$\quad$ Female & 29 & 30 & $P=0.87$ \\
Age (mean \pm SD) & & & \\
EEG finding & $4.11 \pm 1.93$ & $4.17 \pm 2.82$ & $P=0.65 \#$ \\
$\quad$ Normal & $59(73.8 \%)$ & $75(93.8 \%)$ & $X 211.7$ \\
$\quad$ Abnormal & $21(26.2 \%)$ & $5(6.2 \%)$ & $P=0.006$ \\
\hline
\end{tabular}

EEG electroencephalography, NA not applicable,

"Mann-Whitney $U$ test 


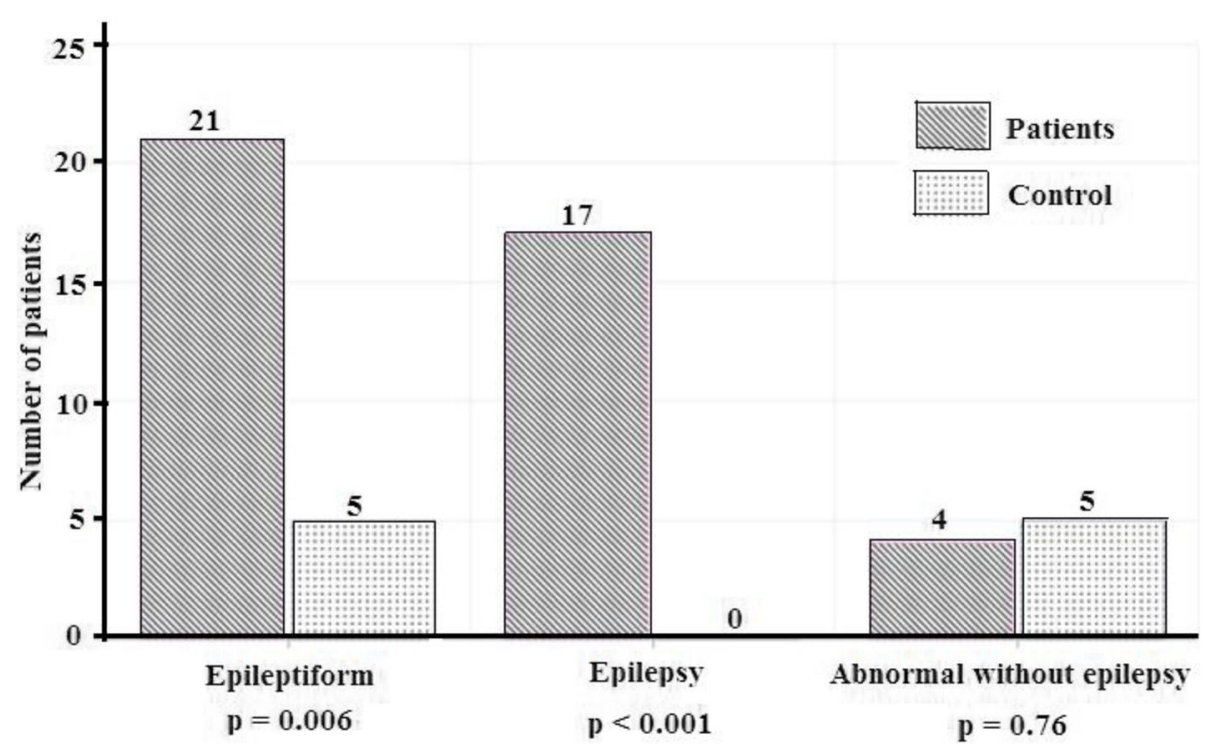

Fig. 1 Abnormal epileptogenic EEG activity in patients with SLI

Table 3 showed statistically significant lower social, cognitive age and average IQ scores in children with epileptiform EEG than children with normal EEG $(P<0.05$, $P<0.05$, and $P<0.01$ respectively).

Regarding the Comprehensive Arabic Language Test, the most affected parts were phonological and pragmatic domains; however, there were no results difference in children with and without epileptiform activity (Table 4).

Spearman correlation showed a highly negative significant correlation between the language, IQ with abnormal EEG and epilepsy $(r=-0.91, P<0.01$ and $r=-$ $0.91, P<0.01$ respectively). Also, there was a moderately negative significant correlation between the cognitive age, social with abnormal EEG, and epilepsy $(r=-0.70, P<$ 0.05 and $r=-0.65, P<0.05$ respectively) (Table 5 ).

\section{Discussion}

Specific language impairment (SLI) is common early in childhood [25]. Prevalence rates have been estimated to be between 3 and 16\%, based on various studies of preschoolers in the UK, Canada, New Zealand, USA, and Hong Kong [26]. SLI or developmental language disorder is diagnosed by exclusion of cognitive and hearing impairment, cerebral palsy, autism, and psychiatric disturbance [3]. Gender preferences, especially among males and positive family history, have been detected [27].

In our study, children with SLI showed a highly significant percentage of abnormal epileptiform discharge and epileptic disorders (in 21 patients (26.2\%) and 17 patients $(21.3 \%)$ respectively), unlike the control group that showed no history of epilepsy. Language disorders in children have been linked to increased frequency of abnormal EEG and epilepsy phenotype [28]. The meta-analysis study of Tuchman 2015 found that the risk for epilepsy in children with language disorders ranged from 8 to 20\% [29]. While Bedair and colleagues 2017 found that about (64\%) children with idiopathic epilepsy were presented with developmental language disorders [30].

Our discovery that a high rate of epileptiform activities even without epilepsy in $26.2 \%$ of children with language impairment indicated a strong connection between epileptic activities and language impairment because repeated subclinical epileptiform activities alone, without

Table 2 Type of epilepsy among patients with SLI

\begin{tabular}{lll}
\hline Type of seizure & Number & Antiepileptic drugs \\
\hline Generalized (tonic and clonic) & $5(29.4 \%)$ & Valproate and or lamotrigine \\
Myoclonic & $2(11.8 \%)$ & Valproate and or levetiracetam \\
Absence & $2(11.8 \%)$ & Ethosuximide and or valproate \\
Temporal lobe & $5(29.4 \%)$ & Carbamazepine and or lamotrigine or levetiracetam \\
Benign childhood epilepsy & $2(11.8 \%)$ & Carbamazepine \\
Other & $1(5.9 \%)$ & Valproate
\end{tabular}




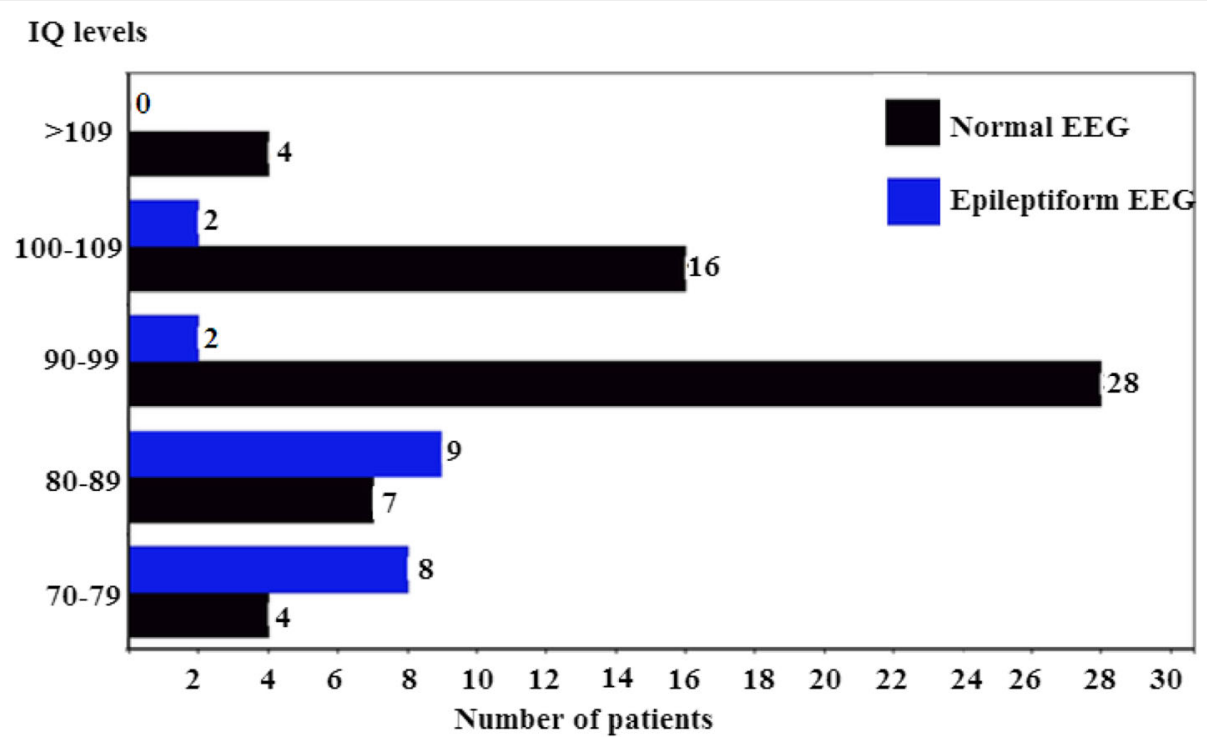

Fig. 2 IQ levels in cases with epileptiform EEG and cases with normal EEG

epilepsy, may alter normal language function. Similarly, Mehta and colleagues who concluded that the presence of generalized abnormalities in EEG and interictal epileptiform discharges are accompanied by speech and language disorder. Although there is no distinct pattern of abnormal EEG in those patients, they advised a standard EEG in them [31].

Seizures have numerous effects on different parts of the brain and may influence the ordinary development of language by different mechanisms. The first, that hereditary, genetic mutations, or structural lesions may prompt both language disorders and epilepsy [32]. Second, interictal epileptiform discharges, cause

Table 3 IQ level, social, and cognitive age assessment in epileptic cases compared with cases with normal EEG

\begin{tabular}{|c|c|c|c|}
\hline & $\begin{array}{l}\text { Epileptiform EEG } \\
(N=21)\end{array}$ & $\begin{array}{l}\text { Normal } \\
\text { EEG } \\
(N=59)\end{array}$ & $\begin{array}{l}\text { Statistical } \\
\text { significance }\end{array}$ \\
\hline \multicolumn{4}{|l|}{ IQ level } \\
\hline • 70-79 & 8 & 4 & $P<0.01$ \\
\hline • 80-89 & 9 & 7 & \\
\hline • 90-99 & 2 & 28 & \\
\hline • 100-109 & 2 & 16 & \\
\hline$\cdot \geq 110$ & 0 & 4 & \\
\hline $\begin{array}{l}\text { - Average } \\
\text { IQ }\end{array}$ & $75.8 \pm 21.3$ & $86.8 \pm 16.7$ & $P<0.01$ \\
\hline \multicolumn{4}{|c|}{ Social score } \\
\hline & $48.8 \pm 19.2$ & $56.97 \pm 20.1$ & $P<0.05$ \\
\hline \multicolumn{4}{|c|}{ Cognitive age (mental age) } \\
\hline & $51.7 \pm 19.7$ & $58.9 \pm 18.2$ & $P<0.05$ \\
\hline
\end{tabular}

EEG electroencephalography, IQ intelligence quotient temporary interruptions in nearby cortical function as well as in more widespread networks. Lastly, childhood is a basic stage for the establishment of pathways related to speech development, and abnormal electrical discharge during this period may impair the typical development [28]. The severity of language impairment changed with the level of EEG epileptiform discharge [33].

In our results, children with abnormal epileptiform discharge on EEG had lower IQ scores compared to patients with normal EEGs $(P<0.01)$. Similarly, Glennon and colleagues found a highly significant correlation between abnormal epileptiform discharge and lower IQ scores [34].

Landi and colleagues 2019 mention that epileptiform activity (EPFA) is often associated with cognitive impairments, mental slowing, communicative, and social disturbances in children [35]. Also, in our study, children with SLI having EPFA were associated with

Table 4 Language assessment in epileptic cases compared with cases with normal EEG

$\begin{array}{lll}\text { Epileptiform EEG } & \text { Normal } & \text { Statistical } \\ (N=21) & \text { EEG } & \text { significance } \\ & (N=59) & \\ \end{array}$

Language assessment by CALT domains $N$ (\%)
(a) Phonology 19 (90.4\%)
$51(86.4 \%) \quad P=0.63$
(b) Semantics 17 (80.9\%)
$46(77.9 \%) \quad P=0.77$
(c)
$13(61.9 \%)$
35 (59.3\%) $\quad P=0.98$
Morphology
(d) Syntax $16(76.2 \%)$
$46(77.9 \%) \quad P=0.86$
(e)
18 (85.7\%)
$48(81.4 \%) \quad P=0.65$ 
Table 5 Spearman correlation between language impairment, cognitive age, social, IQ, and abnormal EEG and epilepsy

\begin{tabular}{llll}
\hline Variable & \multicolumn{3}{l}{ Abnormal EEG and epilepsy } \\
\cline { 2 - 4 } & $\mathbf{r}$ & Correlation & significance \\
\hline IQ & -0.91 & Strong negative & $P<0.01$ \\
Social & -0.65 & Moderate negative & $P<0.05$ \\
Cognitive age & -0.70 & Moderate negative & $P<0.05$ \\
Language impairment & -0.91 & Strong negative & $P<0.01$ \\
\hline
\end{tabular}

significantly lower mental age, cognitive impairment, and social communication. Moreover, Spearman correlation showed a strong significant negative correlation between the language, IQ with abnormal EEG and epilepsy $(r=-0.91, P<0.01$ and $r=-0.91, P$ $<0.01$ respectively).

The main limitations of our study were the restricted number of cases as it was conducted in a single-center only. However, our work provides unique data about the epileptiform activity and its impact on children with SLI in particular IQ scores.

Our study recommended that language dysfunction among children must be considered for evaluation through EEG recordings to find any abnormalities with possible need for medical treatment. Considering medical treatment among those with abnormal epileptic activity may be an essential need to treat their language dysfunction.

\section{Conclusion}

Epileptiform activities even without epilepsy in preschool children may be accompanied by impaired language function. This is more likely to happen in male children and associated with lower IQ level so it is very important to monitor epilepsy or epileptiform activity in children with SLI for early treatment and subsequent normal cognitive functions.

\section{Abbreviations}

CALT: Comprehensive Arabic Language Test; CP: Cerebral palsy; CT: Computed tomography; EEG: Electroencephalography; EPFA: Epileptiform activity; IED: Interictal epileptiform discharges; ILAE: International League Against Epilepsy; IQ: Intelligence quotient; SA: Social age; SB5: Stanford-Binet Intelligence Scale Fifth Edition; SD: Standard deviation; SLI: Specific language impairment; SQ: Social quotient; VSMS: Vineland Social Maturity Scale

\section{Acknowledgements}

Not applicable.

\section{Authors' contributions}

$A E$, the main author, participated in the study design, coordination, and collection of the data and sequence alignment, and helped to draft the manuscript. SE carried out the phoniatric assessment for patients and helped to draft the manuscript. MA collected the data, participated in the sequence alignment, and helped to draft the manuscript. All authors read and approved the final manuscript.

\section{Funding}

This research received no specific grant from any funding agency in the public, commercial, or not-for-profit sectors.

\section{Availability of data and materials}

The datasets generated and analyzed during the current study are not publicly available due to institutional limitations, yet they are available from the corresponding author on reasonable request.

\section{Ethics approval and consent to participate}

This study was approved by the local ethics committee Institutional Research Board (IRB) of Departments of Neurology, Mansoura Faculty of Medicine, Egypt.

Code RP. 19.10.45 date 30 October 2019. Patients and their families were told about the study in detail and written informed consent was taken.

\section{Consent for publication}

Not applicable.

\section{Competing interests}

The authors declare that they have no competing interests.

\section{Author details}

${ }^{1}$ Departments of Neurology, Mansoura University, Mansoura, Egypt.

${ }^{2}$ Departments of Phoniatric, Mansoura University, Mansoura, Egypt.

Received: 16 June 2020 Accepted: 7 January 2021

Published online: 03 March 2021

\section{References}

1. Tomas E, Vissers C. Behind the scenes of developmental language disorder: time to call neuropsychology back on stage. Front Hum Neurosci. 2019;12: 517.

2. Kraft SJ, De Thorne LS. The brave new world of epigenetics: embracing complexity in the study of speech and language disorders. Curr Dev Disord Rep. 2014;1:207.

3. Reilly S, Tomblin B, Law J, McKean C, Mensah FK, Morgan A, et al. Specific language impairment: a convenient label for whom? Int J Lang Commun Disord. 2014;49(4):416-51.

4. Laasonen M, Smolander S, Lahti-Nuuttila PM, Lajunen HR, Heinonen K, Pesonen AK, et al. Understanding developmental language disorder -the Helsinki longitudinal SLI study: a study protocol. BMC Psychol. 2018;6:24.

5. Ghandour H, Eldin SK, Sallam Y, Mahmoud S. Associated comorbidities of specific language impairment. Benha Med J. 2018;35:115-21.

6. Westby C. Social-emotional outcomes for children with SLI. Word Mouth. 2017:28(4):1-5.

7. Kim EH, Ko TS. Cognitive impairment in childhood-onset epilepsy: up-todate information about its causes. Korean J Pediatr. 2016:59(4):155-64.

8. Syam UK, Thomas SV. Epileptiform activity in the electroencephalogram of 6-year-old children of women with epilepsy. Ann Indian Acad Neurol. 2016; 19:318-22.

9. Holmes GL. What is more a harmful, seizure or epileptic EEG abnormalities? Is there any clinical data? Epileptic Disord. 2014;16:S12-22.

10. Ung H, Cazares C, Nanivadekar A, Kini L, Wagenaar J, Becker D, et al. Interictal epileptiform activity outside the seizure onset zone impacts cognition. Brain. 2017;140(8):2157-68.

11. McTaque A, Howell KB, Cross JH, Kurian MA, Scheffer IE. The genetic landscape of the epileptic encephalopathies of infancy and childhood. Lancet Neurol. 2016:15:304-16.

12. Staley K. Molecular mechanisms of epilepsy. Nat. Neurosci. 2015;18:367-72.

13. Faught $\mathrm{E}$, Karakis I, Drane DL. The impact of interictal discharges on performance. Curr Neurol Neurosci Rep. 2018;18(12):88.

14. Luz-Escamilla L, Morales-González JA. Association between interictal epileptiform discharges and autistic spectrum disorder. Brain Sci. 2019;9(8):185.

15. Esmael A, Elsherbeny S, Abbas M. Specific Language Impairment (SLI) in children may caused by epileptic brain activity. In: Abstracts of the 6th Congress of the European Academy of Neurology, Virtual; 2020.

16. Kuratani J, Pearl PL, Sullivan LR, Riel-Romero RMS, Cheek J, Stecker MM, Orta DSJ, Selioutski O, Sinha SR, Drislane FW, Tsuchida TN. American Clinical Neurophysiology Society Guideline 5: Minimum Technical Standards for Pediatric Electroencephalography. Neurodiagn J. 2016;56(4):266-75. 
17. Kane N, Acharya J, Benickzy S, Caboclo L, Finnigan S, Kaplan PW, et al. A revised glossary of terms most commonly used by clinical electroencephalographers and updated proposal for the report format of the EEG findings. Clin Neurophysiol Pract. 2017;2:170-85.

18. Ghacibeh GA, Fields C. Interictal epileptiform activity and autism. Epilepsy Behav. 2015:47:158-62.

19. Scheffer IE, Berkovic S, Capovilla G, et al. ILAE classification of the epilepsies: Position paper of the ILAE Commission for Classification and Terminology. Epilepsia. 2017;58:512.

20. Fisher RS, Cross JH, French JA, Higurashi N, Hirsch E, Jansen FE, et al. Operational classification of seizure types by the International League Against Epilepsy: Position Paper of the ILAE Commission for Classification and Terminology. Epilepsia. 2017;58:522-30.

21. Beretta S, Carone D, Zanchi C, Bianchi E, Pirovano M, Trentini C, et al. Longterm applicability of the new ILAE definition of epilepsy. Results from the PRO-LONG study. Epilepsia. 2017;58:1518-23.

22. Kaufman AS. IQ Testing 101. New York: Springer Publishing; 2009. p. 112.

23. Singh S, Pandey S, Agarwal V. A comparative study of Vineland Adaptive Behavior Scale-II and Vineland Social Maturity Scale on children and adolescents with intellectual disability. J Indian Assoc Child Adolesc Ment Health. 2019;15(1):27-38.

24. El-Maghraby R. Comprehensive Arabic Language test as a tool for assessing delayed language-impaired Egyptian children [MD thesis]. Alexandria: Faculty of Medicine, Alexandria University; 2008

25. Al-Fadhli KY, Al-Bunaian NA. Prevalence and social influences of delayed language development in preschool-age Saudi children. Int I Sci Res. 2017; 6:6-391.

26. Wallace IF, Berkman ND, Watson LR, Coyne-Beasley T, Wood CT, Cullen K, Lohr KN. Screening for speech and language delay in children 5 years old and younger: a systematic review. Pediatrics. 2015;136(2):e448-62.

27. Gharib BA, El Bannab MM, Khalila M, Abou Heikal MM. Prevalence and etiology of communication disorders in children Alexandria University Children's Hospital, Egypt. Alex J Pediatr. 2017;30:17-25.

28. Fiona MB, Aaron LC, Brenda EP. Language dysfunction in pediatric epilepsy. J Pediatr. 2018;194:13-21

29. Tuchman R. Autism and cognition within epilepsy: social matters. Epilepsy Curr. 2015;15(4):202-5.

30. Bedair HM, Mohamed MK, Abdou RM, El Kafrawy Fl. Concurrent language disorders in children with idiopathic epilepsy. Egypt J Otolaryngol. 2017; 33(3):603-9.

31. Mehta B, Chawla VK, Parakh M, Parakh P, Bhandari B, Gurjar AS. EEG abnormalities in children with speech and language impairment. J Clin Diagn Res. 2015;9(7):4-7.

32. Stafstrom CE, Carmant L. Seizures and epilepsy: an overview for neuroscientists. Cold Spring Harb Perspect Med. 2015;5(6):a022426.

33. Sánchez Fernández I, Loddenkemper T, Galanopoulou AS, Moshé SL. Should epileptiform discharges be treated? Epilepsia. 2015;56(10):1492-504.

34. Glennon JM, Weiss-Croft L, Harrison S, Cross JH, Boyd SG, Baldeweg T. Interictal epileptiform discharges have an independent association with cognitive impairment in children with lesional epilepsy. Epilepsia. 2016;57: $1436-42$.

35. Landi S, Petrucco L, Sicca F, Ratto GM. Transient Cognitive Impairment in Epilepsy. Front Mol Neurosci. 2019;11:458.

\section{Publisher's Note}

Springer Nature remains neutral with regard to jurisdictional claims in published maps and institutional affiliations.

\section{Submit your manuscript to a SpringerOpen ${ }^{\circ}$ journal and benefit from:}

- Convenient online submission

- Rigorous peer review

- Open access: articles freely available online

High visibility within the field

- Retaining the copyright to your article

Submit your next manuscript at $\boldsymbol{\nabla}$ springeropen.com 